
\title{
28 Research Suare \\ Detection and follow-up of chronic health conditions in Rio de Janeiro - the impact of residency training in family medicine
}

Adelson Jantsch ( $\square$ adelson.smsrio@gmail.com )

Rio de Janeiro State University

Bo Burström

Karolinska Institute

Gunnar Nilsson

Karolinska Institute

Antônio de Leon

Rio de Janeiro State University

\section{Research Article}

Keywords: Primary Health Care, Family Practice, Health Workforce, Developing Countries

Posted Date: January 9th, 2021

DOI: https://doi.org/10.21203/rs.3.rs-143052/v1

License: (9) This work is licensed under a Creative Commons Attribution 4.0 International License. Read Full License

Version of Record: A version of this preprint was published at BMC Family Practice on November 13th, 2021. See the published version at https://doi.org/10.1186/s12875-021-01542-5. 


\section{Abstract}

There is a need for evidence that residency training in family medicine (RTFM) can benefit the care of patients in primary care in low- and middle-income countries. We tested the hypothesis that two years of RTFM enables doctors to better detect chronic health conditions $(\mathrm{CHC})$ while requesting fewer laboratory exams and providing more follow-up visits. We performed a retrospective longitudinal observational analysis of medical consultations from 2013 to 2018 in primary care in Rio de Janeiro, comparing doctors without RTFM (Generalists) versus family physicians (FPs). Multivariate multilevel binomial regression models estimated the risks of patients being diagnosed for a list of $31 \mathrm{CHCs}$, having a followup visit for these $\mathrm{CHCs}$, and having laboratory tests ordered from a list of 30 exams. 569.289 patients had 2.908.864 medical consultations performed by 734 generalists and 231 FPs. Patients seen by FPs were at a higher risk of being detected for most of the CHCs, at a lower risk of having any of the 30 LTs requested, and at higher risk of having a follow-up visit in primary care. RTFM can make physicians more skilled to work in primary care. Policymakers must prioritize investments in RTFM to make primary care truly comprehensive.

\section{Introduction}

Capacity building of human resources for primary health care (PHC) is a sensitive issue in global health. ${ }^{1}$ For many low- and middle-income countries ${ }^{2}$ (LMIC) the inability to train health care providers is a critical structural problem. ${ }^{3,4}$ Family medicine (FM) is a key element that adds comprehensiveness to PHC. 5,6 However, Residency Training in FM (RTFM) - the gold-standard for post-graduate training of medical health care providers in PHC - is usually not available or, at most, is undervalued and incipient in LMIC. Furthermore, the idea that PHC can easily be performed by any physician without specialized training is a common misconception among many policymakers in countries where selective $\mathrm{PHC}$ is the rule. ${ }^{7}$

Family physicians (FPs) are trained to provide comprehensive patient-centered care, ${ }^{8,9}$ managing the most prevalent health conditions in the community, and making good use of the resources available. ${ }^{10,11}$ In high-income countries (HIC) with strong PHC, FM is a well-established medical specialty and FPs comprise the majority of the medical workforce. ${ }^{12}$ Nevertheless, leaders in FM and primary care providers routinely advocate for improvements, ${ }^{13}$ showing that strong PHC leads to better performance on health indicators while spending less money. ${ }^{14,15}$ Studies from LMIC showing the RTFM's impact on the quality of care may encourage policymakers to invest in capacity building of human resources for PHC. ${ }^{16-18}$

Being able to diagnose prevalent chronic health conditions (CHCs), making rational use of laboratory tests and provide follow-up consultations are necessary competencies that any physician working in PHC must have. ${ }^{10,19,20}$ This study tests the hypothesis that RTFM enables FPs to be more competent to detect $\mathrm{CHC}$ while requesting fewer laboratory exams and providing more follow-up visits for patients with $\mathrm{CHC}$. It aims specifically to estimate the risks of patients (1) being diagnosed for a $\mathrm{CHC}$; (2) having a laboratory test (LT) requested in one medical consultation; and (3) having a follow-up visit in PHC, according to the 
type of physician, i.e., FPs or physicians without RTFM (Generalists). Finally, (4) we aimed to determine the Population Attributable Fractions and estimate what would be the change in the amount of LTs requested and incident cases of $\mathrm{CHC}$ per year if all medical consultations were carried out by FPs.

\section{Methods}

STUDY DESIGN AND DATA SOURCE

This is a retrospective longitudinal observational analysis of medical consultations performed by FPs and Generalists in the public PHC system in the Rio de Janeiro municipality from January 2013 to December 2018. Each medical consultation (the unit of analysis) was considered as a binary event (diagnosed versus non-diagnosed, LT requested versus LT not requested, follow-up consultation versus non-follow up consultation). The Rio de Janeiro Practice-based Research Network (RioPBRN) provided the dataset for this research, compiling Information from 999.364 patients registered in one health district in Rio de Janeiro. This study was approved by the Rio de Janeiro Municipal Health Department (RJ-MHD) research ethics board and it is registered under the number 03795118.0.0000.5279.

\section{SETTING}

The Family Health Strategy (Estratégia de Saúde da Família - FHS) is the Brazilian federal policy for public PHC launched in 1994 to provide structural organization and financial support to the municipal Family Health Teams (FHTs) ${ }^{21}$ FHTs are formed by one physician, one nurse, and four to six community health workers (CHW) to provide care for up to 4.000 patients in a given catchment area.

Despite the positive results in public health of the $\mathrm{FHS}^{22-25}$ its expansion depended entirely on the municipalities' adherence to the policy. Rio de Janeiro, the last Brazilian capital to adopt the FHS, expanded the number of FHTs from 2008 to 2016, increased its coverage from 3.5\% to $70 \%$ of the population, ${ }^{26}$ created new community-based primary care clinics and made strong investments to expand RTFM. ${ }^{27}$ More than 600 FPs have graduated so far from the three FM residency programs established in the city, increasing the provision and fixation of FPs in PHC.

Today, $25 \%$ of the FHTs in Rio de Janeiro have trained FPs, $65 \%$ have physicians without RTFM (Generalists), and 10\% have physicians enrolled at the More Doctors Program, a federal policy established in 2013 for provision and fixation of Brazilian and foreign physicians in PHC. ${ }^{28}$ This distribution created a convenient quasi-experimental design to address the effect of RTFM in the provision of PHC. 
OUTCOMES

Three groups of outcomes were analyzed as dichotomous events: (1) detection of CHCs; (2) LTs requests; and (3) follow-up visits.

The risk of a patient being detected with a $\mathrm{CHC}$ was estimated for each condition considering only consultations among patients that have not had that specific condition diagnosed prior to the encounter. A list with $31 \mathrm{CHC}$ was created combining the ICD-10 codes from three different frameworks: (a) the Brazilian list of ambulatory-care sensitive conditions, ${ }^{29}$ (b) the Charlson comorbidity index ${ }^{30}$ and (c) the Elixhauser comorbidity index. ${ }^{31}$ Chronic hepatitis was added to the list and Neoplastic diseases were divided into five subdomains: Cancer (general), Cancer in men (Neoplasia of male genital organs), Cancer in women (Neoplasia of female genital organs), Breast cancer (women only) and Metastatic cancer. Three conditions - Hypertension, Type 2 Diabetes Mellitus (T2DM), and Hypothyroidism - were categorized in two different ways: one using only ICD10 codes and the other using specific clinical criteria. Table 1 summarizes the list with the $31 \mathrm{CHCs}$, the respective ICD10 codes, and clinical criteria.

For the risk of a LT being requested in one consultation, a list with the 30 most requested LTs in the sample was created. For LH, FSH, Rubella IgG and Rubella IgM, only women were considered as patients at risk, while PSA considered only men. For each LT in the list, consultations were categorized as having the LT requested (event) or not having the LT requested (no-event).

The risk of patients with a $\mathrm{CHC}$ having a follow-up consultation was estimated considering all patients seen in a month by each physician and consultations were clustered and ordered among each individual physician. Undiagnosed patients' consultations were considered as no-event and diagnosed patients' consultations were considered as events. The consultation in which the patient was diagnosed for the specific $\mathrm{CHC}$ was excluded.

The outcomes were chosen to approach three common questions that policymakers in LMIC have about the necessity of RTFM to work in PHC: "RTFM will make doctors more capable of detecting CHC?", "Will they order less LTs?" and "Will they provide more follow-up visits? These are all common events in ambulatory care and analyzing the effect that RTFM has in their occurrence may bring relevant evidence for policymakers and health managers. The rationale behind the choice for these outcomes goes aligned with the definition of FM from the Brazilian, ${ }^{10}$ Canadian $^{20}$ and European ${ }^{19}$ curricula for FM, i.e., that experts in FM are skilled clinicians that are capable of managing a full range of health conditions, making efficient use of diagnostic and therapeutic interventions.

In Rio de Janeiro, a comprehensive list of LTs is available for all doctors and nurses in the public PHC system to make use of. With no restriction for requesting any LT, the decision to order it or not will rely 
mostly on the doctor's clinical judgment facing the patient's health needs. In this scenario, concerns that patients would not have access to LTs due to poor availability and scarce resources moves from "lack of healthcare" to the "overuse that does not add value for patients and may even cause harm". ${ }^{32}$ Supported by several medical associations, campaigns such as Choosing Wisely ${ }^{33}$ and the concept of Quaternary Prevention ${ }^{34}$ try to engage physicians and patients in conversations about unnecessary tests, treatments and procedures, showing that "doing more does not mean doing better". If RTFM helps doctors to make more efficient use of diagnostic tests, patients treated by FPs will probably have fewer LTs requested in their consultations. 
Table 1: List of chronic health conditions according to their ICD10 codes and clinical criteria.

Hypertension I10-115

(ICD10)

Hypertension At least one measurement $>140 / 90 \mathrm{mmHg}$

clinical criteria

Diabetes Mellitus E10-E14

(ICD10)

Diabetes clinical At least one glycemia $>126 \mathrm{mg} / \mathrm{dl}$ or A1C hemoglobin $>6.5 \%$

criteria

Hypothyroidism E00-E03, E890

coded

Hypothyroidism ICD codes (E00-E03, E890) and at least one TSH > $5 \mathrm{mcg} / \mathrm{dL}$

clinical criteria

HIV/AIDS B20-B24, Z21, F024, R75

Drug addiction F11-F16, F18, F19, Z715, Z722

Depression F204, F313-F315, F32, F33, F341, F412, F432

Psychosis F20, F22-F25, F28, F29, F302, F312, F315

Alcohol abuse $\quad$ F10, E52, G621, I426, K292, K700, K703, K709, T51, Z502, Z714, Z721

Cardiac $\quad$ 1441-1443, 1456, 1459, 147-I49, R001, Z950

arrythmias

Ischemic heart I I20-I22, I238, I248, I249, I250-I252, I255, I256, I258, I259

disease

Peripheral artery $\quad 170,171,1731,1738,1739,1771,1790,1792$, K551, K558, K559, Z958, Z959

disease

Heart failure $\quad$ 1099, I110, I130, I132, 1420, I425-1429, I43, I50, P290, J81

Kidney failure $\quad$ 1120, I131, N032-N037, N052-N057, N18, N19, N250, Z490-Z492, Z992

Osteoarthritis M15- M19, M2, M40-M43

Rheumatic L93, L940, L941, L943, M05, M06, M08, M10, M11, M120, M123, M30, M310,

disorders $\quad$ M313, M315, M32-M36, M45, M461, M468, M469

Neurological G10-G13, G20-G22, G254, G255, G312, G318, G319, G32, G35-G37, G931, G934, disorders G43, G44, G45, G46, G47, G5, G6, G7, G8, R47

Epilepsy G40, G41, R56

Stroke G45, G46, H340, 16

Dementia F00-F03, F051, G30, G310, G311

COPD I278, I279, J40-J44, J47, J60-J67, J684, J701, J703 
Asthma J45, J46

Chronic hepatitis

B180, B181, B182, B188, B189, K713, K714, K715, K730, K731, K732, K738, K739

Cirrhosis of the

B18, K700-K704, K709, K713, K715, K717, K73, K74, K760, K762-K764, K768, liver K769, Z944, I85, I864, 1982, K711, K721, K729, K765-K767

Cancer (general) C0, C1, C2, C3, C4, C64-C69, C7, C8, C9

Cancer in men $\quad$ C60-C63

Cancer in women $\quad$ C51-C58

Breast cancer $\quad$ C50

Metastatic $\quad \mathrm{C} 77, \mathrm{C} 78, \mathrm{C} 79, \mathrm{C} 80$

Cancer

EXPOSURES

Physicians were divided into two categories: (1) Generalists - doctors without RTFM (reference group); and (2) Family physicians (FPs) - graduated FPs, FM preceptors and residents enrolled in the FM residency programs.

Residents in FM spend two years working 48 hours a week in a community-based primary care clinic under the full supervision of a senior FP (FM preceptor) sharing responsibilities for the same patients in one FHT. Their clinical and academic ${ }^{35,36}$ activities aim to develop the skills, competencies, and attitudes a FP must have to practice in PHC. They are aligned with the National Committee for Medical Residencies $(\mathrm{CNRM})^{37}$ and with the Brazilian Society of Family and Community Medicine (SBMFC) ${ }^{10}$ Information about other forms of post-graduate training or specialization were not available in the database and were not taken into account, nor the number of years in practice for any doctor.

INDEPENDENT VARIABLES

Models were adjusted for information regarding the consultation context, such as patient's age, patient's Charlson Comorbidity Index ${ }^{30}$ (except when the dependent variable was a $\mathrm{CHC}$ component of the index, 
e.g., HIV/AIDS, heart failure, stroke or COPD, since the same information would be present on both sides of the equation), and medical category in charge of the consultation (generalists or FPs).

The Charlson Comorbidity Index added to the model's information about patients' morbidity burden, assuming that those with a higher morbidity burden would be more likely to have more follow-up visits and to develop other $\mathrm{CHCs}$, and would require more LTs. A dichotomous variable identifying if the consultation was a prenatal care visit was also included. As for time effects dummy variables for months and years were regarded in all models.

Patients' information that does not change over time, such as patient's sex and the Social Development Index (SDI) of the neighborhood were also considered. The SDI is a composite indicator combining information about sanitation, schooling, income, and housing conditions from every household in the FHT catchment area. ${ }^{38}$ It represents the grade of social development of the neighborhood where the patient lives, varying from 0 (least developed) to 1 (most developed).

All clinics and FHTs in this sample have the same human resources, equipment, and physical structure. Generalists and FPs were evenly distributed across the neighborhoods, clinics, and FHTs.

\section{STATISTICAL ANALYSES}

Multilevel binomial regression models were built to estimate the relative risks between Generalists (reference group) and FPs of each one of the three types of outcomes happening in medical consultations in primary care.

For LTs requested in one consultation and the detection of $\mathrm{CHCs}$, consultations were clustered and ordered per each individual patient. This created a hierarchical data structure in which consultations were nested within patients, hence taking into account the correlation among consultations from the same patient. These models were adjusted for first level covariates (consultation), i.e., patient's age, patient's Charlson Comorbidity Index, prenatal care consultation, time, and medical category; and for second level covariates - SDI and patient's sex.

For follow-up consultations, the hierarchical data structure chosen had consultations (first level) nested within doctors (second level). This structure captures the availability of consultations (access to healthcare) for each $\mathrm{CHC}$ between Generalists and FPs. In this way, RRs represent the risk of FPs offer one consultation for a specific $\mathrm{CHC}$ in a given period, compared to generalists. These models were adjusted for first level covariates (consultation), i.e., patient's age, patient's Charlson Comorbidity Index, 
and prenatal care consultation; for second level covariates (months, SDI and patient's sex) and third level covariates (medical category).

With the RRs from the previous models, Population Attributable Fractions (PAFs) for each LT and CHC were calculated to estimate the change in the number of LTs requested and in the number of incident cases of $\mathrm{CHCs}$ per year in the same health care district if all medical consultations were performed by trained FPs. ${ }^{39,40}$ Data processing and statistical analysis were performed using R version 3.6.2 and Ime4 package.

\section{Results}

Over a period of 6 years, 569.289 patients (335.346 women and 233.943 men) had 2.908 .864 medical consultations performed by 964 different doctors (734 generalists and 231 FPs) in 30 PHC clinics and 196 FHTs. Doctors worked non-concurrently throughout the period of analysis and generalists accounted for $66.4 \%$ of the consultations in the sample, while FPs were responsible for $33.6 \%$. There was a small but statistically significant ( $p$-value for t-test $<0.05$ ) difference in patients' age and SDI distributions among Generalists' and FPs' populations. Patients from the wealthiest $(S D I=0.689)$ and the poorest areas $(\mathrm{SDI}=0.416)$ were seen by both categories. (table 2$)$

Table 2: Number of medical consultations and patients' characteristics according to each medical category in the study sample. Rio de Janeiro, Brazil, 2015 - 2018.

\begin{tabular}{|c|c|c|c|c|c|c|}
\hline \multirow[t]{3}{*}{$\begin{array}{l}\text { Medical } \\
\text { category }\end{array}$} & \multirow{3}{*}{$\begin{array}{l}\text { Number of } \\
\text { doctors } \\
\mathrm{N}(\%)\end{array}$} & \multirow{3}{*}{$\begin{array}{l}\text { Consultations } \\
\mathrm{N}(\%)\end{array}$} & \multirow{3}{*}{$\begin{array}{l}\text { SDI } \\
\text { mean } \\
\text { (SD) }\end{array}$} & \multirow{3}{*}{$\begin{array}{l}\text { Patients } \\
\text { age } \\
\text { mean } \\
(\mathrm{SD})\end{array}$} & \multicolumn{2}{|c|}{$\begin{array}{l}\text { Consultations according to } \\
\text { sex }-\mathrm{N}(\%)\end{array}$} \\
\hline & & & & & & \\
\hline & & & & & Women & Men \\
\hline \multirow[t]{2}{*}{ Generalists } & \multirow[t]{2}{*}{734 (76.1) } & \multirow{2}{*}{$\begin{array}{l}1.932 .297 \\
(66.4)\end{array}$} & \multirow{2}{*}{$\begin{array}{l}0.573 \\
(0.03)\end{array}$} & \multirow{2}{*}{$\begin{array}{l}40.3 \\
(24.0)\end{array}$} & \multirow{2}{*}{$\begin{array}{l}1.267 .756 \\
(65.6)\end{array}$} & 664.541 \\
\hline & & & & & & $(34.4)$ \\
\hline \multirow{2}{*}{$\begin{array}{l}\text { Family } \\
\text { physicians }\end{array}$} & 231 & 976.567 & \multirow{2}{*}{$\begin{array}{l}0.581 \\
(0.03)\end{array}$} & 40.71 & \multirow[t]{2}{*}{$645.175(66.1)$} & 331.392 \\
\hline & (23.9) & (33.6) & & $(23.1)$ & & $(33.1)$ \\
\hline
\end{tabular}

Hypertension, T2DM, and Hypothyroidism, the three CHCs that were categorized using both ICD 10 and clinical criteria, presented a similar pattern: using ICD10 codes, FPs were less likely to diagnose these 
conditions, while using clinical criteria, FPs were more likely to diagnose all of them.

FPs were more likely to diagnose the majority of the remaining 24 domains of $\mathrm{CHC}$ in the list. The exceptions were Epilepsy, presenting a lower risk of being diagnosed by FPs, while Rheumatic disorders, Cirrhosis of the liver and Neoplasia of male genital organs presented similar risk between generalists and FPs. Metastatic cancer presented a higher but not statistically significant risk of being diagnosed by FPs.

The risk of a patient having a follow-up visit was higher for FPs running the consultation. Even for those patients that have $\mathrm{CHC}$ that FPs were less likely to diagnose, patients have a higher chance of having a follow-up visit if their doctor is a FP. Around 7\% of the patients coded as having Hypertension or T2DM would no longer be coded as such, decreasing by 1208 , and 384 the number of incident cases per year, respectively. On the other hand, in all domains, except those that RR for medical categories were not statistically significant, an increasing number of incident cases would be seen. Hypertension and T2DM (according to clinical criteria), Heart failure, Stroke, Asthma, and Osteoarthritis would have the biggest increment in the number of incident cases, while Drug addiction, Alcohol abuse, Kidney failure, and Peripheral artery disease would have the biggest relative increase of new cases. (table 3 ) 
Table 3: Relative risks (RR) and 95\% confidence intervals for a patient being diagnosed for a chronic health condition in one medical consultation and RRs for follow; up consultations happening in a month in PHC between Generalists (reference) and Family physicians. Rio de Janeiro, Brazil, 20132018.

Family physicians

Condition

Hypertension - ICD10

Hypertension - clinical criteria

Diabetes Mellitus - ICD10

Diabetes Mellitus - clinical criteria

Hypothyroidism - ICD10‡

Hypothyroidism - clinical criteria

AIDS

Drug addiction

Alcohol abuse

Depression

Psychosis

Cardiac arrhythmias

Peripheral artery disease

Ischemic heart disease

Heart failure

Kidney failure

Osteoarthritis

Rheumatic disorders $\ddagger$

Neurological disorders

Epilepsy

Stroke

Dementia

COPD

Asthma

Chronic hepatitis
Detection of $\mathrm{CHCs}$

$0.84(0.82-0.86)$

$1.15(1.13-1.17)$

$0.81(0.79-0.84)$

$1.07(1.04-1.11)$

0.97 (0.91-1.04)

$1.51(1.25-1.82)$

1.19 (1.09-1.29)

1.98 (1.76-2.22)

1.72 (1.54-1.91)

1.19 (1.14-1.26)

1.20 (1.11-1.30)

1.31 (1.19-1.45)

2.41 (2.05-2.82)

1.38 (1.27-1.49)

1.69 (1.56-1.83)

1.82 (1.64-2.02)

1.11 (1.07-1.15)

$1.00(0.92-1.10)$

1.29 (1.24-1.34)

$0.86(0.79-0.94)$

1.44 (1.34-1.55)

1.28 (1.16-1.42)

1.11 (1.02-1.21)

1.28 (1.21-1.36)

1.31 (1.10-1.57)

Page $11 / 24$
Follow-up

1.18 (1.10-1.27)

1.54 (1.41-1.68)

1.14 (1.09-1.20)

$1.43(1.32-1.55)$

1.60 (1.45-1.77)

2.25 (1.86-2.72)

1.72 (1.55-1.91)

2.64 (2.22-3.14)

2.53 (2.13-2.99)

1.89 (1.70-2.11)

1.77 (1.58-1.98)

1.93 (1.70-2.19)

2.80 (2.26-3.47)

2.01 (1.77-2.27)

2.66 (2.34-3.01)

2.44 (2.08-2.87)

1.77 (1.57-1.98)

1.74 (1.56-1.93)

1.94 (1.75-2.15)

1.37 (1.24-1.51)

1.73 (1.55-1.94)

1.78 (1.56-2.05)

1.56 (1.41-1.72)

1.71 (1.51-1.93)

1.85 (1.59-2.15) 


\begin{tabular}{|lll|} 
Cirrhosis of the liver $\neq$ & $1.03(0.90-1.18)$ & $1.99(1.77-2.24)$ \\
\hline Cancer & $1.26(1.17-1.36)$ & $1.78(1.43-2.20)$ \\
Neoplasia - Men $\ddagger$ & $1.11(0.92-1.33)$ & $2.14(1.75-2.62)$ \\
Neoplasia - Women & $1.34(1.11-1.62)$ & $2.08(1.77-2.46)$ \\
Breast cancer & $1.42(1.21-1.67)$ & $1.69(1.06-2.70)$ \\
Metastatic cancerł & $1.47(0.96-2.26)$ & $1.18(1.10-1.27)$
\end{tabular}

¥: Non-statistically significant in the multivariate binomial models.

All p-values were smaller than 0.001, except for Neoplasia - Women ( $p$-value < 0.005) and nonstatistically significant for those marked with $¥$

Multilevel binomial regression models adjusted by patients' age, sex, time, Charlson comorbidity index, and SDI.

Generalists (reference group) are doctors without residency training in Family Medicine.

Family physicians are graduated FPs, FM preceptors and residents enrolled in Family Medicine training.

Patients seen by FPs present a lower risk of having any of the 30 LTs requested during one consultation, with a RR lower than $50 \%$ for Glucose, Ova \& parasite, Urea, Sodium, T3, T4, PSA Rubella IgG and IgM, Uric acid, Calcium, AST, ALT and LDL cholesterol. (table 4) 
Table 4: Population Attributable Fractions (PAFs) and the change in the absolute numbers of chronic health conditions detected per year in a scenario in which all medical consultations were performed by Family Physicians. Rio de Janeiro, 2013- 2018.

\begin{tabular}{|c|c|c|c|}
\hline Condition & $\begin{array}{l}\text { Population attributable } \\
\text { fraction }\end{array}$ & $\begin{array}{l}\text { Cases per } \\
\text { year }\end{array}$ & $\begin{array}{l}\text { Number of cases added or } \\
\text { subtracted }\end{array}$ \\
\hline Hypertension - ICD10 & $-11.2(-9.8 ;-12.7)$ & 15901 & $-1781(-1558 ;-2019)$ \\
\hline $\begin{array}{l}\text { Hypertension - clinical } \\
\text { criteria }\end{array}$ & $9.5(8.3 ; 10.7)$ & 11681 & $1110(970 ; 1250)$ \\
\hline Diabetes Mellitus - ICD10 & $-13.5(-11.2 ;-15)$ & 5562 & $-751(-623 ;-834)$ \\
\hline $\begin{array}{l}\text { Diabetes Mellitus - clinical } \\
\text { criteria }\end{array}$ & $4.5(2.6 ; 7)$ & 4089 & $184(106 ; 286)$ \\
\hline Hypothyroidism - ICD10 & $-2(-6.2 ; 2.6)$ & 755 & $-15(-47 ; 20)$ \\
\hline $\begin{array}{l}\text { Hypothyroidism - clinical } \\
\text { criteria }\end{array}$ & $28.9(15.3 ; 42.7)$ & 79 & $23(12 ; 34)$ \\
\hline AIDS & $11.9(5.8 ; 17.6)$ & 415 & $49(24 ; 73)$ \\
\hline Drug addiction & $49(40.2 ; 57.5)$ & 197 & $97(79 ; 113)$ \\
\hline Alcohol abuse & $38.5(30.4 ; 46.3)$ & 237 & $91(72 ; 110)$ \\
\hline Depression & $11.9(8.9 ; 15.9)$ & 1119 & $133(100 ; 178)$ \\
\hline Psychosis & $12.4(7 ; 18.1)$ & 466 & $58(33 ; 84)$ \\
\hline Cardiac arrhythmias & $18.7(11.9 ; 26)$ & 412 & $77(49 ; 107)$ \\
\hline Peripheral artery disease & $63.6(51.6 ; 75)$ & 114 & $73(59 ; 86)$ \\
\hline Ischemic heart disease & $22.4(16.4 ; 28)$ & 499 & $112(82 ; 140)$ \\
\hline Heart failure & $37.2(31.3 ; 43.1)$ & 482 & $179(151 ; 208)$ \\
\hline Kidney failure & $42.7(35 ; 50.5)$ & 270 & $115(94 ; 136)$ \\
\hline Osteoarthritis & $7(4.5 ; 9.5)$ & 3800 & $266(171 ; 361)$ \\
\hline Rheumatic disordersł & $0(-5.5 ; 6.4)$ & 503 & $0(-28 ; 32)$ \\
\hline Neurological disorders & $17.6(14.8 ; 20.3)$ & 2092 & $368(310 ; 425)$ \\
\hline Epilepsy & $-9.8(-4.1 ;-15)$ & 579 & $-57(-24 ;-87)$ \\
\hline Stroke & $25.5(20.3 ; 30.8)$ & 586 & $149(119 ; 180)$ \\
\hline Dementia & $17(10.1 ; 24.5)$ & 310 & $53(31 ; 76)$ \\
\hline COPD & $7(1.3 ; 13)$ & 532 & $37(7 ; 69)$ \\
\hline Asthma & $17(13 ; 21.3)$ & 782 & $133(102 ; 167)$ \\
\hline
\end{tabular}




\begin{tabular}{|c|c|c|c|}
\hline Chronic hepatitis & $18.7(6.4 ; 31.8)$ & 84 & $16(5 ; 27)$ \\
\hline Cirrhosis of the liver & $2(-6.9 ; 11.3)$ & 212 & $4(-15 ; 24)$ \\
\hline Cancer & $15.9(10.7 ; 21.3)$ & 627 & $100(67 ; 134)$ \\
\hline Neoplasia - Men‡ & $7(-5.5 ; 19.7)$ & 92 & $6(-5 ; 18)$ \\
\hline Neoplasia - Women & $20.3(7 ; 34.1)$ & 81 & $16(6 ; 28)$ \\
\hline Breast cancer & $24.5(13 ; 36.3)$ & 122 & $30(16 ; 44)$ \\
\hline Metastatic cancer & $27(-2.7 ; 58.8)$ & 16 & $4(0 ; 9)$ \\
\hline
\end{tabular}

In a scenario where all medical consultations would be performed by FPs, T3, T4, Ova \& parasite, Uric acid, PSA, Urea and LDL cholesterol would have their demand reduced by more than $50 \%$. In absolute numbers, Hemograms, Urea, Uric acid, LDL cholesterol and Urinalysis would experience the greater impact, with almost 20.000 Hemograms and more than 10.000 Urea, Uric acid, and LDL cholesterol tests avoided per year. (table 5) 
Table 5: Relative risks and 95\% confidence intervals for a laboratory test (LT) being requested in one medical consultation comparing Family physicians and Generalists (adjusted for age, sex, social development index and Charlson comorbidity index) in PHC, the respective Population Attributable Fractions (PAFs) and the change in the absolute numbers of LTs requested in a scenario in which all medical consultations were performed by Family Physicians. Rio de Janeiro, 2013- 2018.

\begin{tabular}{|c|c|c|c|c|}
\hline Laboratory test & $\begin{array}{l}\text { Family } \\
\text { Physicians } \\
(95 \% \mathrm{Cl})\end{array}$ & $\begin{array}{l}\text { PAF } \\
(95 \% \\
\mathrm{Cl})\end{array}$ & $\begin{array}{l}\text { Absolute number of } \\
\text { LTs requested per } \\
\text { year }\end{array}$ & $\begin{array}{l}\text { Absolute change in the total } \\
\text { number of LTs requested per } \\
\text { year } \\
(95 \% \mathrm{Cl})\end{array}$ \\
\hline Hemogram & $\begin{array}{l}0.53(0.53- \\
0.54)\end{array}$ & $\begin{array}{l}-37.1 \\
(-36.1 \\
-37.1)\end{array}$ & 51757 & $-19202(-18684 ;-19202)$ \\
\hline Creatinine & $\begin{array}{l}0.85(0.84- \\
0.86)\end{array}$ & $\begin{array}{l}-10.5 \\
(-9.8 \\
-11.2)\end{array}$ & 43746 & $-4593(-4287 ;-4900)$ \\
\hline Urea & $\begin{array}{l}0.29(0.28- \\
0.29)\end{array}$ & $\begin{array}{l}-61.9 \\
(-61.9 \\
-63.1)\end{array}$ & 22577 & $-13975(-13975 ;-14246)$ \\
\hline Sodium & $\begin{array}{l}0.42(0.41- \\
0.43)\end{array}$ & $\begin{array}{l}-47.8 \\
(-46.8 \\
-48.9)\end{array}$ & 10517 & $-5027(-4922 ;-5143)$ \\
\hline Potassium & $\begin{array}{l}0.73(0.72- \\
0.75)\end{array}$ & $\begin{array}{l}-19.7 \\
(-18.1 \\
-20.5)\end{array}$ & 18265 & $-3598(-3306 ;-3744)$ \\
\hline Glucose & $\begin{array}{l}0.46(0.45- \\
0.47)\end{array}$ & $\begin{array}{l}-43.8 \\
(-42.8 \\
-44.8)\end{array}$ & 9072 & $-3974(-3883 ;-4064)$ \\
\hline $\begin{array}{l}\text { A1C } \\
\text { Hemoglobin }\end{array}$ & $\begin{array}{l}0.64(0.63- \\
0.65)\end{array}$ & $\begin{array}{l}-27.2 \\
(-26.3 \\
-28.1)\end{array}$ & 25720 & $-6996(-6764 ;-7227)$ \\
\hline $\begin{array}{l}\text { Total } \\
\text { cholesterol }\end{array}$ & $\begin{array}{l}0.81(0.8- \\
0.82)\end{array}$ & $\begin{array}{l}-13.5 \\
(-12.7 \\
-14.2)\end{array}$ & 34673 & $-4681(-4403 ;-4924)$ \\
\hline HDL cholesterol & $\begin{array}{l}0.94(0.93- \\
0.95)\end{array}$ & $\begin{array}{l}-4.1 \\
(-3.4 \\
-4.8)\end{array}$ & 31127 & $-1276(-1058 ;-1494)$ \\
\hline LDL cholesterol & $\begin{array}{l}0.41(0.41- \\
0.42)\end{array}$ & $\begin{array}{l}-48.9 \\
(-47.8 \\
-48.9)\end{array}$ & 22163 & $-10838(-10594 ;-10838)$ \\
\hline Triglycerides & $\begin{array}{l}0.82(0.81- \\
0.83)\end{array}$ & $\begin{array}{l}-12.7 \\
(-12 ; \\
-13.5)\end{array}$ & 33828 & $-4296(-4059 ;-4567)$ \\
\hline Uric acid & $\begin{array}{l}0.23(0.22- \\
0.23)\end{array}$ & $\begin{array}{l}-69(-69 ; \\
-70.2)\end{array}$ & 15603 & $-10766(-10766 ;-10953)$ \\
\hline
\end{tabular}




\begin{tabular}{|c|c|c|c|c|}
\hline TSH & $\begin{array}{l}0.71(0.7- \\
0.73)\end{array}$ & $\begin{array}{l}-21.3 \\
(-19.7 \\
-22.2)\end{array}$ & 11679 & $-2488(-2301 ;-2593)$ \\
\hline Triiodothyronine & $\begin{array}{l}0.08(0.06- \\
0.09)\end{array}$ & $\begin{array}{l}-88.4 \\
(-87 ; \\
-91.2)\end{array}$ & 791 & $-699(-688 ;-721)$ \\
\hline Thyroxine & $\begin{array}{l}0.13(0.12- \\
0.15)\end{array}$ & $\begin{array}{l}-81.6 \\
(-79 ; \\
-83)\end{array}$ & 886 & $-723(-700 ;-735)$ \\
\hline free Thyroxine & $\begin{array}{l}0.56(0.55- \\
0.58)\end{array}$ & $\begin{array}{l}-34.3 \\
(-32.5 \\
-35.2)\end{array}$ & 5432 & $-1863(-1765 ;-1912)$ \\
\hline Bilirubin & $\begin{array}{l}0.78(0.75- \\
0.81)\end{array}$ & $\begin{array}{l}-15.8 \\
(-13.5 ; \\
-18.1)\end{array}$ & 2304 & $-364(-311 ;-417)$ \\
\hline AST & $\begin{array}{l}0.48(0.47- \\
0.49)\end{array}$ & $\begin{array}{l}-41.8 \\
(-40.9 \\
-42.8)\end{array}$ & 9181 & $-3838(-3755 ;-3929)$ \\
\hline ALT & $\begin{array}{l}0.47(0.46- \\
0.48)\end{array}$ & $\begin{array}{l}-42.8 \\
(-41.8 \\
-43.8)\end{array}$ & 9363 & $-4007(-3914 ;-4101)$ \\
\hline $\begin{array}{l}\text { Alkaline } \\
\text { phosphatase }\end{array}$ & $\begin{array}{l}0.69(0.67- \\
0.71)\end{array}$ & $\begin{array}{l}-23 \\
(-21.3 \\
-24.7)\end{array}$ & 3505 & $-806(-747 ;-866)$ \\
\hline Gamma-GT & $\begin{array}{l}0.64(0.62- \\
0.66)\end{array}$ & $\begin{array}{l}-27.2 \\
(-25.5 \\
-28.9)\end{array}$ & 4386 & $-1193(-1118 ;-1268)$ \\
\hline ESR & $\begin{array}{l}0.74(0.71- \\
0.77)\end{array}$ & $\begin{array}{l}-18.9 \\
(-16.6 \\
-21.3)\end{array}$ & 1957 & $-370(-325 ;-417)$ \\
\hline Ova \& parasite & $\begin{array}{l}0.09(0.08- \\
0.11)\end{array}$ & $\begin{array}{l}-87 \\
(-84.3 \\
-88.4)\end{array}$ & 604 & $-525(-509 ;-534)$ \\
\hline Urinalysis & $\begin{array}{l}0.67(0.67- \\
0.68)\end{array}$ & $\begin{array}{l}-24.7 \\
(-23.8 \\
-24.7)\end{array}$ & 41333 & $-10209(-9837 ;-10209)$ \\
\hline Calcium & $\begin{array}{l}0.44(0.42- \\
0.46)\end{array}$ & $\begin{array}{l}-45.8 \\
(-43.8 \\
-47.8)\end{array}$ & 1866 & $-855(-817 ;-892)$ \\
\hline LH & $\begin{array}{l}0.56(0.52- \\
0.61)\end{array}$ & $\begin{array}{l}-34.3 \\
(-29.8 \\
-38)\end{array}$ & 674 & $-231(-201 ;-256)$ \\
\hline $\mathrm{FSH}$ & $\begin{array}{l}0.6(0.56- \\
0.64)\end{array}$ & $\begin{array}{l}-30.7 \\
(-27.2 ; \\
-34.3)\end{array}$ & 863 & $-265(-235 ;-296)$ \\
\hline
\end{tabular}




\begin{tabular}{|c|c|c|c|c|}
\hline Rubella IgG & $\begin{array}{l}0.48(0.41- \\
0.55)\end{array}$ & $\begin{array}{l}-41.8 \\
(-35.2 ; \\
-48.9)\end{array}$ & 210 & $-88(-74 ;-103)$ \\
\hline Rubella IgM & $\begin{array}{l}0.47(0.4- \\
0.54)\end{array}$ & $\begin{array}{l}-42.8 \\
(-36.1 \\
-49.9)\end{array}$ & 216 & $-92(-78 ;-108)$ \\
\hline PSA & $\begin{array}{l}0.36(0.34- \\
0.37)\end{array}$ & $\begin{array}{l}-54.1 \\
(-53.1 \\
-56.3)\end{array}$ & 4365 & $-2361(-2318 ;-2457)$ \\
\hline \multicolumn{5}{|c|}{ All p-values were smaller than 0.001} \\
\hline \multicolumn{5}{|c|}{ Generalists (reference group) are doctors without residency training in Family Medicine. } \\
\hline
\end{tabular}

Figure 1 presents a summary picture of patients with at least one $\mathrm{CHC}$ seen in PHC by FPs and Generalists throughout the analysis. Each dot represents, for each category in a month, the average amount of LTs ordered (size) and the average amount of CHC that patients have (y-axis). They don't represent reasons for encounter, but the number of morbidities that patients have listed in their records. For Hypertension, T2DM, and Hypothyroidism only patients that met clinical criteria were considered. Over the years, the amount of $\mathrm{CHC}$ increase for both groups of patients, but that increment is bigger for FPs' patients, that also have fewer LTs requested.

\section{Discussion}

The hypothesis tested here show that RTFM can make doctors more likely to diagnose a larger set of $\mathrm{CHC}$, provide more follow-up visits to their patients and request fewer LTs in primary care. Moreover, it seems that RTFM makes doctors more accurate when diagnosing Hypertension, T2DM and Hypothyroidism, the three domains analyzed using ICD10 codes and clinical criteria.

These findings support the definition of FPs as skilled clinicians able to cover the "full range of health conditions" and to use "the prevalence and incidence of an illness in the community" during their decision-making processes. ${ }^{10,11,20}$ This is important evidence showing that FM is a key element to bring comprehensiveness to $\mathrm{PHC}$. Being more capable of detecting a large set of $\mathrm{CHC}$ together with the increased offer of follow-up visits to patients with CHCs means not only that more patients will have their health issue identified but that they will also have more medical visits to manage their $\mathrm{CHC}$, which is key for the success of the treatment.

Furthermore, the higher risk of patients being diagnosed for a $\mathrm{CHC}$ by FPs can be representing the detection of conditions when symptoms are mild or non-specific, in the early stages. ${ }^{9,41}$ If patients with undifferentiated symptoms leave the consultation room without a diagnosis - or a clear diagnostic plan 
- they will potentially go to another health service to find a solution to their problem. Their diagnosis will be delayed, and it will probably be made when the symptoms become more pronounced. For conditions such as Cancer, HIV, Cardiac arrhythmias, and Kidney failure this delay can make a difference between a successful treatment and an avoidable death. The changes in the absolute numbers in table 3 does not mean that those patients are not being diagnosed, but they are either trying to solve their problems somewhere else or having their diagnosis delayed.

The disparity of RRs observed in the three domains analyzed using ICD10 codes and clinical criteria Hypertension, T2DM and Hypothyroidism - also brings to discussion the matter of payment-forperformance schemes, overdiagnosis and accuracy.

Hypertension and T2DM are CHCs that are targeted by the payment-for-performance municipal schemes since the PHC reform took place. ${ }^{26}$ One performance measurement is the number of patients coded for Hypertension or T2DM reaching levels of blood pressure below $140 / 90 \mathrm{mmHg}$ or $6.5 \%$ for A1C hemoglobin. If patients with prediabetes or prehypertension are coded as T2DM and Hypertension, their control target would be already reached, making these patients accounted as successfully treated. Another reason for that difference could be the focus that the federal government gives to cardiovascular diseases, via selective programs for screening and management of Hypertension and T2DM. With financial and political incentives for FHTs to pay extra attention to these conditions, it is not unusual for FHTs to reserve specific days or shifts of the week in their schedule exclusively for patients with Hypertension and/or T2DM, restricting access for patients with other health conditions. ${ }^{42,43}$

Payment-for-performance initiatives are designed to improve the quality of care, but if it comes with an increased risk of overdiagnosis, ${ }^{44}$ the potential damage that can result from that (overtreatment, unnecessary procedures, and stigmatization) can be more harmful than beneficial. ${ }^{45}$ Furthermore, a higher number of Hypertension and T2DM cases should be followed by a proportionally increased number of actual cardiovascular diseases (Heart failure, Ischemic heart disease, Stroke, Cardiac arrhythmias, and Peripheral artery disease), but that is not the case.

One could argue that those patients were not subject to overdiagnosis, but were actual cases that were properly managed and, therefore, have the development of cardiovascular diseases prevented. That could be true for cardiovascular diseases, however, the increased risk that FP's patients have to be diagnosed for HIV, Dementia, Drug addiction, Psychosis, Kidney failure, Cardiac arrhythmias, and Cancer suggests the opposite. These are conditions that need not only good clinical knowledge and skills to be suspected and diagnosed but competencies and attitudes that RTFM programs are meant to develop. ${ }^{10,19,20,46}$

The higher risk of detection of HIV among FPs illustrates this situation. Rapid tests for HIV and syphilis are available in every public PHC clinic in Rio de Janeiro. Doctors, nurses, and nurse technicians are trained by the RJ-MHD to perform this point-of-care test. They learn the procedure but raising suspicion and offering the test to a patient demands attitudes that are beyond the knowledge and skills needed to perform the test. 
Overdiagnosis can be also the case for Epilepsy, a CHC referring to recurrent seizures, but patients with isolated seizures or even febrile seizures are commonly labeled as epileptic.

Mental health conditions (Depression, Psychosis, Drug addiction and Alcohol abuse) being more likely to be diagnosed by FPs also show how RTFM can make doctors more sensitive to perceiving conditions that are commonly neglected in the community, which require an active attitude to be suspected, investigated and diagnosed. In other words, if the professional just waits for the patient to declare having problems with alcohol or drugs, very few patients will be diagnosed and will have an opportunity for treatment. ${ }^{47}$

It is worth noting the contrast between the amount of LTs requested and the number of CHCs diagnosed, e.g., FPs request $64 \%$ less PSA than Generalists, but the detection of Cancer in male genital organs (93\% are Prostate Cancer) is similar. The number of glucose and A1C hemoglobin exams is 30 to $50 \%$ higher among Generalists, but the number of patients diagnosed by clinical criteria for T2DM and the risk of follow-up consultations favors FPs. This information corroborates the definition of a FP as a "skilled clinician" that makes "effective and efficient use of diagnostic and therapeutic interventions" ${ }^{19,20}$ LTs that would usually be requested for patients with liver damage, i.e., Gamma GT, AST, ALT, and Alkaline phosphatase illustrates the situation very well. They are more often requested by Generalists but conditions that would necessarily need those exams, such as Alcohol abuse and Chronic hepatitis, are more likely to be diagnosed by FPs. Conditions that would also require those exams, such as Cholangitis and Cirrhosis of the liver, could be partially accountable for that difference, but they would hardly explain the whole gap.

Finally, continuity of care can also play an important role in increasing the risk of detection of $\mathrm{CHC}$ among FPs. Since FPs provide more follow-up consultations, their patients will have more opportunities

to be diagnosed for a second or third $\mathrm{CHC}$, a common event in patients with multimorbidity. ${ }^{48}$ Cardiac arrhythmias, Kidney failure and Peripheral artery disease, conditions that are consequences of having a prior diagnose of T2DM or Hypertension, exemplify this phenomenon.

\section{STRENGTHS AND LIMITATIONS}

The decision to address the subject by approaching policymakers' and managers' general questions about the effect of RTFM in healthcare limits our conclusions to the evidence that two years of training increases the risk of CHCs being detected, of follow-up visits being offered and lowers the risk of LTs being requested in medical consultations in primary care. To infer that RTFM allows doctors to provide 
better health care in every aspect of medical practice based solely on the results from our study would be a disproportionate and unfair generalization. To conclude that RTFM influences other types of outcomes, such as lowering mortality, decreasing hospital admissions, and promoting quality of life, different approaches and research methods must be taken.

However, using real-world data from a real experience in a middle-income setting shows us evidence about the real performance of physicians in primary care and how it can be affected by two years of training in FM, making it more likely that the implementation of this type of a training program in other scenarios will produce similar results.

\section{Conclusion}

Being a competent clinician, able to cover the full range of health conditions and making effective use of diagnostic and therapeutic interventions are competencies that FPs must have to work in PHC, and RTFM seems to be effective in promoting them among physicians in Rio de Janeiro. Furthermore, the development of these competencies helps to expand access to health care, making PHC more comprehensive, effective, and socially accountable. Policymakers in LMIC must consider that PHC systems will not move from selective interventions to become truly comprehensive and effective without investments in capacity building of human resources. Regarding the medical workforce, this transformation will not happen without investments in RTFM.

\section{References}

1. Frenk, J. et al. Health professionals for a new century: transforming education to strengthen health systems in an interdependent world. Lancet 376, 1923-1958 (2010).

2. Willcox, M. L. et al. Human resources for primary health care in sub-Saharan Africa: progress or stagnation? Hum. Resour. Health 13, (2015).

3. Donabedian, A. The Quality of Care: How Can It Be Assessed? JAMA J. Am. Med. Assoc. (1988). doi:10.1001/jama.1988.03410120089033

4. WHO. The World Health Report 2008 - Primary Health Care: Now More Than Ever. The World Health Report (2008).

5. Ponka, D. et al. The Contribution of Family Medicine and Family Medicine Leaders to Primary Health Care Development in Americas - from Alma-Ata to Astana and beyond. Cien. Saude Colet. 25, 12151220 (2020).

6. Kidd, M. The Contribution of Family Medicine to Improving Health Systems: A Guidebook from the World Organization of Family Doctors. (CRC Press, 2013).

7. Anderson, M. I. P. \& Rodrigues, R. D. Formação de especialistas em Medicina de Família e Comunidade no Brasil: dilemas e perspectivas. Rev. Bras. Med. Fam. e Comunidade 6, 19-20 (2011).

8. Stewart, M. et al. Patient-centered Medicine: Transforming the clinical method. (Radcliffe Medical Press, 2014). 
9. Freeman, T. R. McWhinney's Textbook of Family Medicine. Textbook of Family Medicine (2016). doi:10.1093/med/9780199370689.001.0001

10. SBMFC. Currículo Baseado em Competências para Medicina de Família e Comunidade. Currículo Baseado em Competências para Medicina de Família e Comunidade (2015). Available at: http://www.sbmfc.org.br/wp-content/uploads/media/Curriculo Baseado em Competencias(1).pdf. (Accessed: 27th February 2020)

11. EURACT. The EURACT Educational Agenda Of General Pratctice/Family Medicine. (2005).

12. Starfield, B., Shi, L. \& Macinko, J. Contribution of Primary Care to Health Systems and Health. Milbank Q. 83, 457-502 (2005).

13. Arya, N. et al. Family medicine around the world: overview by region. Can. Fam. Physician 63, 436441 (2017).

14. Macinko, J., Starfield, B. \& Shi, L. The contribution of primary care systems to health outcomes within Organization for Economic Cooperation and Development (OECD) countries, 1970-1998. Heal. Serv Res 38, 831-865 (2003).

15. Starfield, B. Primary Care and Health: A Cross-National Comparison. JAMA J. Am. Med. Assoc. (1991). doi:10.1001/jama.1991.03470160100040

16. Dye, C. et al. The World Health Report 2013: Research for Universal Health Coverage. (2014).

17. Ponka, D. The Besrour Papers: Seeking evidence for family medicine. Afr J Prim Heal. Care Fam Med 1-2 (2017). doi:10.4102/phcfm.v9i1.1559

18. Ponka, D. et al. Developing the evidentiary basis for family medicine in the global context. Can. Fam. physician Médecin Fam. Can. 61, 596-600 (2015).

19. EURACT Council. THE EUROPEAN DEFINITION OF GENERAL PRACTICE/FAMILY MEDICINE. 11 (2011). Available at: https://www.woncaeurope.org/sites/default/files/documents/Definition EURACTshort version revised 2011.pdf. (Accessed: 1st January 2020)

20. Shaws, E., Oandasan, I. \& Fowler, N. CanMEDS-FM 2017: A competency framework for family physicians across the continuum. The College of Family Physicians of Canada - Le Collège des Médecins de Famille du Canada 21 (2017). Available at: https://www.cfpc.ca/uploadedFiles/Resources/Resource_Items/Health_Professionals/CanMEDSFamily-Medicine-2017-ENG.pdf. (Accessed: 27th February 2020)

21. Macinko, J. \& Harris, M. J. Brazil's Family Health Strategy - Delivering Community-Based Primary Care in a Universal Health System. N. Engl. J. Med. 372, 2177-2181 (2015).

22. Macinko, J., de Fátima Marinho de Souza, M., Guanais, F. C. \& da Silva Simões, C. C. Going to scale with community-based primary care: An analysis of the family health program and infant mortality in Brazil, 1999-2004. Soc. Sci. Med. (2007). doi:10.1016/j.socscimed.2007.06.028

23. Rasella, D., Aquino, R. \& Barreto, M. L. Reducing Childhood Mortality From Diarrhea and Lower Respiratory Tract Infections in Brazil. Pediatrics 126, (2010). 
24. Rasella, D., Harhay, M. O., Pamponet, M. L., Aquino, R. \& Barreto, M. L. Impact of primary health care on mortality from heart and cerebrovascular diseases in Brazil: A nationwide analysis of longitudinal data. $B M J$ (2014). doi:10.1136/bmj.g4014

25. Aquino, R., Oliveira, N. F. De \& Barreto, M. L. Impact of the Family Health Program on Infant Mortality in Brazilian Municipalities. Am. J. Public Health 99, 87-93 (2009).

26. Soranz, D., Pinto, L. F. \& Penna, G. O. Themes and Reform of Primary Health Care (RCAPS) in the city of Rio de Janeiro , Brazil article. Cien. Saude Colet. 1327-1338 (2016). doi:10.1590/141381232015215.01022016

27. Justino, A. L. A., Oliver, L. L. \& Melo, T. P. de. Implementation of the Residency Program in Family and Community Medicine of the Rio de Janeiro Municipal Health Department , Brazil article. 1471-1480 (2016). doi:10.1590/1413-81232015215.04342016

28. Campos, G. W. de S. \& Nilton, P. J. Primary care in Brazil, and the Mais Médicos (More Doctors) Program in the Unified Health System: achievements and limits. Cien. Saude Colet. 21, 2655-2663 (2016).

29. Alfradique, M. E. et al. Internações por condições sensíveis à atenção primária: a construção da lista brasileira como ferramenta para medir o desempenho do sistema de saúde (Projeto ICSAP - Brasil). Cad. Saude Publica 25, 1337-1349 (2009).

30. Charlson, M. E. et al. The Charlson comorbidity index is adapted to predict costs of chronic disease in primary care patients. J. Clin. Epidemiol. 61, 1234-1240 (2008).

31. Elixhauser, A., Steiner, C., Harris, D. R., Coffey, R. M. \& Elixhauser, A. Measures for Use with Administrative Data Comorbidity. Med. Care 36, 8-27 (1998).

32. Levinson, W. et al. 'Choosing Wisely': a growing international campaign. BMJ 1-9 (2014). doi:10.1136/bmjqs-2014-003821

33. Choosing wisely Canada. Thirteen Things Physicians and Patients Should Question. (2018).

34. Jamoulle, M. Quaternary prevention, an answer of family doctors to overmedicalization. Int. J. Heal. Policy Manag. 4, 61-64 (2015).

35. Izecksohn, M. M. V., Teixeira Junior, J. E., Stelet, B. P. \& Jantsch, A. G. Preceptorship in Family and Community Medicine: challenges and achievements in a Primary Health Care in progress. Cien. Saude Colet. 737-746 (2016). doi:10.1590/1413-81232017223.332372016

36. Programa de Residência em Medicina de Família e Comunidade da Secretaria Municipal de Saúde do Rio de Janeiro. Multiplica: método de ensino para programas de residência em medicina de família e comunidade. (SBMFC, 2016).

37. Ministério da Educação. Comissão Nacional de Residência Médica. (2020). Available at: http://portal.mec.gov.br/residencias-em-saude/residencia-medica.

38. Cavallieri, F. \& Lopes, G. P. Índice de Desenvolvimento Social - IDS: comparando as realidades microurbanas da cidade do Rio de Janeiro. (2008).

39. Mansournia, M. A. \& Altman, D. G. Population attributable fraction. BMJ 757, 2-3 (2018). 
40. World Health Organization. Population Attributable Fraction (PAF). Health statistics and information systems (2020). Available at: https://www.who.int/healthinfo/global_burden_disease/metrics_paf/en/. (Accessed: 25th April 2020)

41. Greenhalgh, T. Primary Health Care: Theory and Practice. (Wiley, 2007).

42. Feitosa, I. de O. \& Pimentel, A. HIPERDIA: práticas de cuidado em uma unidade de saúde de Belém, Pará. Rev. NUFEN 8, (2016).

43. Silva, J. V. M. da, Mantovani, M. de F., Kalinke, L. P. \& Ulbrich, E. M. Hypertension and Diabetes Mellitus Program evaluation on user's view. Rev Bras Enferm 68, 626-32 (2015).

44. Kale, M. S. \& Korenstein, D. Overdiagnosis in primary care: Framing the problem and finding solutions. BMJ 362, (2018).

45. Norman, A. H., Russell, A. J. \& Merli, C. The Quality and Outcomes Framework: Body commodification in UK general practice. Soc. Sci. Med. (2016). doi:10.1016/j.socscimed.2016.10.009

46. Cantillon, P., Wood, D. F. \& Yardley, S. ABC of Learning and Teaching in Medicine. (BMJ Books, 2017).

47. WHO Mental Health Forum 2019. Enhancing Country Action on Mental Health Summary report. (2019).

48. Mercer, S. W., Salisbury, C. \& Fortin, M. ABC of Multimorbidity. (2014).

\section{Figures}




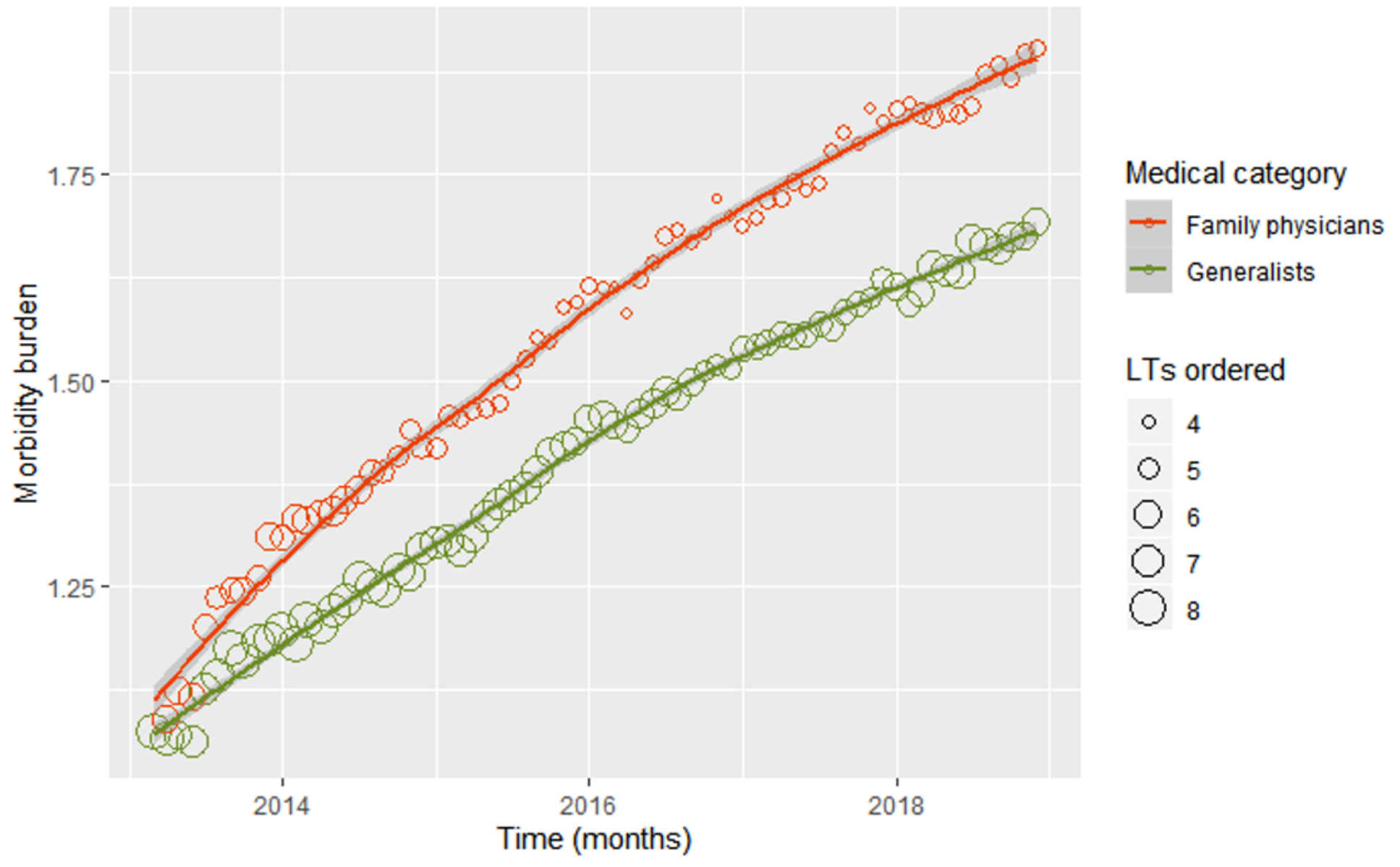

\section{Figure 1}

Average morbidity burden of adult patients seen in PHC and average amount of laboratory tests (LTs) requested in one consultation according to the medical category of the health care provider from January 2013 to December 2018, in Rio de Janeiro, Brazil. Morbidity burden is a discrete variable considering one unit for each of the following chronic health conditions ( $\mathrm{CHC}$ ): Hypertension, T2DM, complications related to diabetes, Alcohol abuse, Drug addiction, Psychosis, Depression, Hypothyroidism, Cardiac arrhythmia, Osteoarthritis, Valvular disease, Anemia, Neurological diseases, Stroke, Dementia, Ischemic heart disease, Heart failure, Peripheral arterial disease, COPD, Kidney failure, HIV/AIDS, Chronic hepatitis, Cirrhosis of the liver, Rheumatic diseases, Epilepsy, Cancer, Metastatic cancer. Only consultations where patients had at least one $\mathrm{CHC}$ were considered. Medical category comprehends Family physicians and Generalists, that are doctors with or without residency training in Family Medicine, respectively. Smooth curve fitted using local polynomial regression (LOESS) 